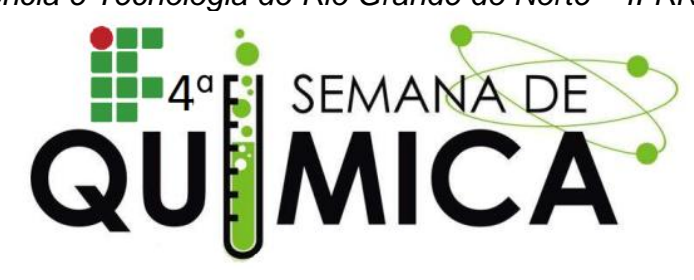

\title{
GERENCIAMENTO, TRATAMENTO E REAPROVEITAMENTO DE RESÍDUOS DE CROMO EM LABORATÓRIO DE ENSINO.
}

SOUZA, A. L. S. (IC) (IFRN-NC), MADRUGA, M. F. S.(IC) (IFRN-NC), SILVA, A. C. O. (PQ) (IFRN-NC)

Palavras Chave: Resíduo, cromo, reaproveitamento.

\section{INTRODUÇÃO}

Para minimizar a produção de resíduos químicos, é recomendável o gerenciamento no laboratório de química, diminuindo volumes e concentrações de reagentes químicos, reutilizando, recuperando e reciclando os resíduos químicos, eliminando agentes tóxicos encontrados em laboratórios e assim preservando o meio ambiente ${ }^{[1]}$. Este trabalho tem por objetivo o gerenciamento dos resíduos de íons cromo nos laboratórios do IFRN-Nova Cruz, o qual será reciclado e reaproveitado.

\section{METODOLOGIA}

A curva de calibração para o íon $\mathrm{Cr}^{6+}$ através da espectrofotometria foi realizada nas concentrações 2,08, 4,16, 10,4, 20,8, 41,6 mg/L.

A amostra residual de cromo oriunda de experimentos com dicromato de potássio, foi analisada por UV-vis e observado concentração maior que o valor permitido pela legislação para descarte de efluente. Deste modo, foi realizado o reaproveitamento do dicromato de potássio por método de evaporação para possível reutilização em titulação argentimétrica, técnica esta para caracterização do material, onde o material obtido foi utilizado como indicador $\left(\mathrm{K}_{2} \mathrm{Cr}_{2} \mathrm{O}_{7}\right)$, em que $0,1 \mathrm{M} \mathrm{AgNO}_{3}$ foi submetida a padronização com $\mathrm{NaCl} 0,1 \mathrm{M}$ na presença de $\mathrm{K}_{2} \mathrm{Cr}_{2} \mathrm{O}_{7} 5 \%$ e para comparação, foi preparada uma solução de $\mathrm{K}_{2} \mathrm{Cr}_{2} \mathrm{O}_{7}$ P.A. $5 \%$ (m/v).

\section{RESULTADOS E DISCUSSÕES}

A curva de calibração está apresentada na figura 1 com equação da reta de $A=0,0275+0,0659\left[\mathrm{Cr}^{6+}\right]$ e $r=0,9991$.

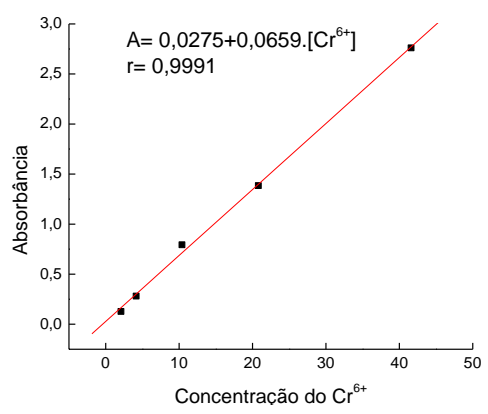

Figura 1 - Curva de calibração para o íon cromo.

A solução contendo resíduo de $\mathrm{Cr}^{6+}$ apresentou concentração de 286 mg/L $(0,028 \%)$, valor superior ao permitido pelo CONAMA. Desta forma, o resíduo foi concentrado de $500 \mathrm{~mL}$ a $2 \mathrm{~mL}$, obtendo uma concentração de $56,9 \times 10^{3} \mathrm{mg} / \mathrm{L}(5,6 \%)$, podendo então a solução de $\mathrm{K}_{2} \mathrm{Cr}_{2} \mathrm{O}_{7}$ ser utilizada na titulação argentimétrica. Os dados da tittulação por $\mathrm{K}_{2} \mathrm{Cr}_{2} \mathrm{O}_{7}$ recuperado e P.A. mostram-se satisfatórios e estão apresentados na tabela 1.

Tabela 1 - Volumes gastos na titulação com a solução de $\mathrm{AgNO}_{3}$ 0,1M.

\begin{tabular}{|c|c|}
\hline \multicolumn{2}{|l|}{ Volume gasto de $\mathrm{AgNO}_{3}$ na titulação de $\mathrm{NaCl}(\mathrm{mL})$} \\
\hline Volume teórico $\mathrm{AgNO}_{3}$ & 10,0 \\
\hline Volume experimental $\mathrm{AgNO}_{3} \operatorname{com~} \mathrm{K}_{2} \mathrm{Cr}_{2} \mathrm{O}_{7}$ P.A. & 10,7 \\
\hline Volume experimental $\mathrm{AgNO}_{3} \mathrm{com} \mathrm{K}_{2} \mathrm{Cr}_{2} \mathrm{O}_{7}$ reciclado & 10,6 \\
\hline \multicolumn{2}{|l|}{ CONCLUSÃO } \\
\hline \multirow{2}{*}{\multicolumn{2}{|c|}{$\begin{array}{l}\text { Diante dos resultados, as amostras de } \\
\mathrm{K}_{2} \mathrm{Cr}_{2} \mathrm{O}_{7} \text { tratadas, poderão ser reutilizadas nas } \\
\text { aulas de Química Analítica Quantitativa. }\end{array}$}} \\
\hline & \\
\hline \multicolumn{2}{|l|}{ REFERÊNCIAS } \\
\hline \multirow{3}{*}{\multicolumn{2}{|c|}{$\begin{array}{l}1 \text { FELISBERTO, R. et al. De resíduo a insumo: a } \\
\text { construção do caminho para uma química mais } \\
\text { limpa através de um projeto de ensino. Quim. } \\
\text { Nova v } 31 \text {. } 1.2008 \text {. }\end{array}$}} \\
\hline & \\
\hline & \\
\hline $\begin{array}{l}\text { Nova, v. } 31, \text { n. 1, } 2008 . \\
2 \text { CONAMA - Conselho Nacional do }\end{array}$ & (2) \\
\hline $\begin{array}{l}\text { mbiente. Ministério do meio am } \\
\text { esolução no } 357 \text {, de } 17 \text { de março de } 20\end{array}$ & \\
\hline
\end{tabular}

